\title{
Development of a Layout Model Suitable for the Food Processing Industry
}

\author{
W. N. C. Wanniarachchi, R. A. R. C. Gopura, and H. K. G. Punchihewa \\ Department of Mechanical Engineering, University of Moratuwa, 10400 Katubedda, Sri Lanka \\ Correspondence should be addressed to H. K. G. Punchihewa; himan@mech.mrt.ac.lk
}

Received 28 February 2016; Accepted 4 May 2016

Academic Editor: Björn Johansson

Copyright @ 2016 W. N. C. Wanniarachchi et al. This is an open access article distributed under the Creative Commons Attribution License, which permits unrestricted use, distribution, and reproduction in any medium, provided the original work is properly cited.

\begin{abstract}
The food processing industry is a subset of the manufacturing sector with unique challenges. Among these, ensuring food hygiene and preventing contamination are two issues of prime importance. Hence, designers have to overcome such challenges when designing facilities suitable for food processing. The paper formulates a model that simplifies the layout planning process for the food processing facilities (FPF) in order to help the designers. A generalised framework that helps to visualise the Facilities Layout Problem (FLP) was initially developed. A layout model for FPF was then developed considering the unique features that need to be present in the layout. The model classifies the areas of FPF into five: primary, secondary, utilities, warehouse, and administration based on the activities and the level of risk present in food processing. It further proposes specific locations for the five sections in the factory layout. In order to test the performance of the framework and the model, a case study was conducted in a malted milk powder processing facility in Sri Lanka by changing its layout according to the proposed model. The framework and the model showed promise in its implementation. However, the approach and the layout model need to be evaluated in further cases in order to ascertain their usability and performance.
\end{abstract}

\section{Introduction}

A facility may be a machine tool, a work centre, a manufacturing cell, a machine shop, a department, or a warehouse [1], and a facility layout is an arrangement of everything needed for production of goods or delivery of services. An efficient layout would ensure increased productivity. Determining the physical organisation of a production system is defined as the facility layout problem (FLP) [2]. It is difficult to resolve due to inherent conflicting objectives and constraints. FLP is known to have a significant impact upon the manufacturing costs, work process, lead time, and productivity [3]. FLP is even more difficult in the food processing industry [3]. Failing to produce food items according to hygiene standards has a direct influence on production efficiency through loss of production and has an even greater effect through loss of consumer confidence [4]. Lapses in ensuring food hygiene can also lead to prosecution in criminal court for negligence and can cause major financial losses to companies.

Food safety and hygiene therefore play a major role in industry and food quality is the result of numerous factors such as physical, biochemical, and microbiological characteristics [5]. Therefore, it is imperative that these factors are considered in layout design in the food processing industry. Many practices such as the hazard analysis and critical control points (HACCP) or good manufacturing practices (GMP) attempt to ensure food safety and hygiene requirements in the food manufacturing process. In order to align with these requirements, layouts need to focus on segregating the work area to control hazards and prevent contamination of the products being manufactured. This focus will ensure that the layouts comply with the requirements of the food industry and avoid modifications required later that usually result in additional costs. However, little research on FLP considering the unique manufacturing requirements of the food processing industry is reported in the literature. Therefore, this paper formulates a model that simplifies the layout planning process for the food processing facilities (FPF). A generalised framework that helps to visualise the FLP was initially developed. Then, a layout model for FPF was proposed considering the unique features that need to be present in the layout. A case study was finally conducted 


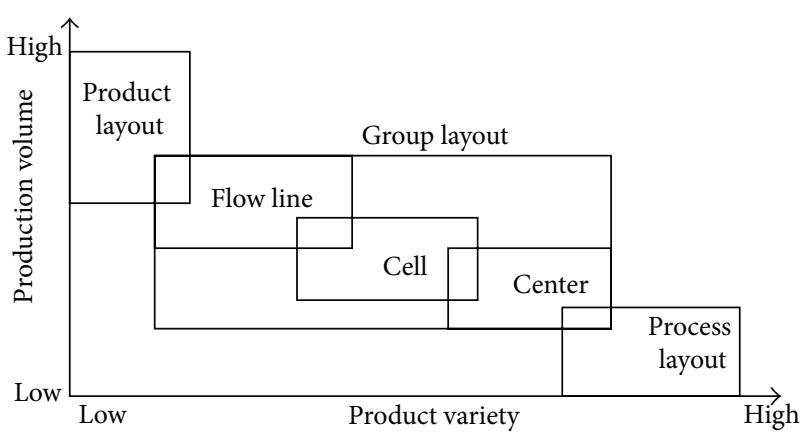

Figure 1: Layout types.

by changing the layout of a malted milk powder processing facility in Sri Lanka according to the proposed model.

The next section of the paper presents the literature review. Section 3 describes the developed framework to visualise the FLP and the layout model is proposed in Section 4. Section 5 evaluates the proposed framework and the model. Results and discussion are presented in Section 6 followed by the conclusion in the last section.

\section{Related Research}

A plant layout is designed to obtain a physical arrangement of different entities of a facility that most economically meets the required output, in terms of both quantity and quality [6]. According to [7], a plant layout ideally involves allocation of space and arrangement of equipment in such a manner that overall operating costs are minimised. Three main types of layouts, product layout, process layout, and group layout, are commonly encountered in manufacturing systems. Group layouts can further be categorised into flow line, cell, and centre [8]. These are shown in Figure 1, and, according to [8], the distinction between these types of layouts is made based on system characteristics such as production volume and product variety. It is reported that a well-designed manufacturing layout can reduce the operating cost by $50 \%$ $[9,10]$.

2.1. Layout Efficiency. In order to assess the efficiency of a layout, key performance indicators (KPIs) are used. The commonly used KPIs are travelling distance (m), distance travelled times weight $(\mathrm{mkg})$, goods movement, personnel movement, overall equipment efficiency (OEE), energy efficiency, and waste generation. However, KPIs suitable for the food manufacturing need to be identified and incorporated into the assessment criteria of layout efficiency in order to address the food safety considerations. This also enables effective determination of the efficiency improvement of the food manufacturing processes when layout modifications are performed.

2.2. Food Processing Technology. The primary concern of food manufacturers is to produce something that is wholesome and safe, that is, free from pathogenic microorganisms and chemical and foreign body contamination [11]. Food items are perishable and become unsuitable for consumption with time. Although it cannot be prevented, one aim of food processing is to slow down the rate of deterioration by selecting appropriate methods of processing, ingredient formulations, packaging, and storage conditions [12]. In order to make food items safe for consumption, food processing plants take measures to eliminate the possibility of microbial, chemical, and physical contamination. Thus, it becomes a key factor of concern, and layout design should essentially help to prevent direct and cross contamination of the products being manufactured. Hence, the layouts of the food processing factories have to be designed to meet food safety requirements on top of production efficiency. This is the main envisaged difference between the layouts of food processing and other manufacturing plants. Thus it can be concluded that the food processing plants add a new dimension to the common layout design problem.

\subsection{Quality Standards Applicable for the Food Processing} Industry. Many guidelines are available to regulate the food manufacturing processes. In the food processing sector, Quality Assurance (QA) systems are used to improve quality and reduce costs whilst HACCP programs are specifically deployed to assure food safety [4]. Based on management principles, HACCP and GMP have been implemented to help plants to maintain high levels of hygiene [4]. HACCP systems establish process control by identifying points in the production process that are most critical to monitor and control in terms of contamination [13]. It is widely recognised in the food industry as an effective approach to establish good production, sanitation, and manufacturing practices that produce food items that are safe to consume [14]. Therefore, it can be concluded that QA and HACCP implemented in concert facilitate improvements in both production efficiency and product safety [15].

Considering the above factors, an area that needs attention in the food processing industry is the relationship between hygiene and the layout of the processing plants. Aspects of food hygiene have been addressed in different disciplines and a considerable amount of knowledge is available. However, this knowledge is not systematically linked to the evaluation and design of layouts for food processing. The literature on layout planning has thus far inadequately addressed the influence of hygiene factors on the specific nature of the food processing companies [4].

\section{Development of Framework}

A systematic process has to be followed in layout design to ensure that the design is in accordance with the production requirement. Therefore, sufficient information to start a layout design process is crucial. The layout design or modification problem becomes even more difficult to resolve when there are practical limitations such as demolition of existing walls and structures, adding more space to an existing facility, accommodating the complexity of a manufacturing process, and maintaining capacity and flexibility of a plant. The cost of implementation of a new layout and the available time 


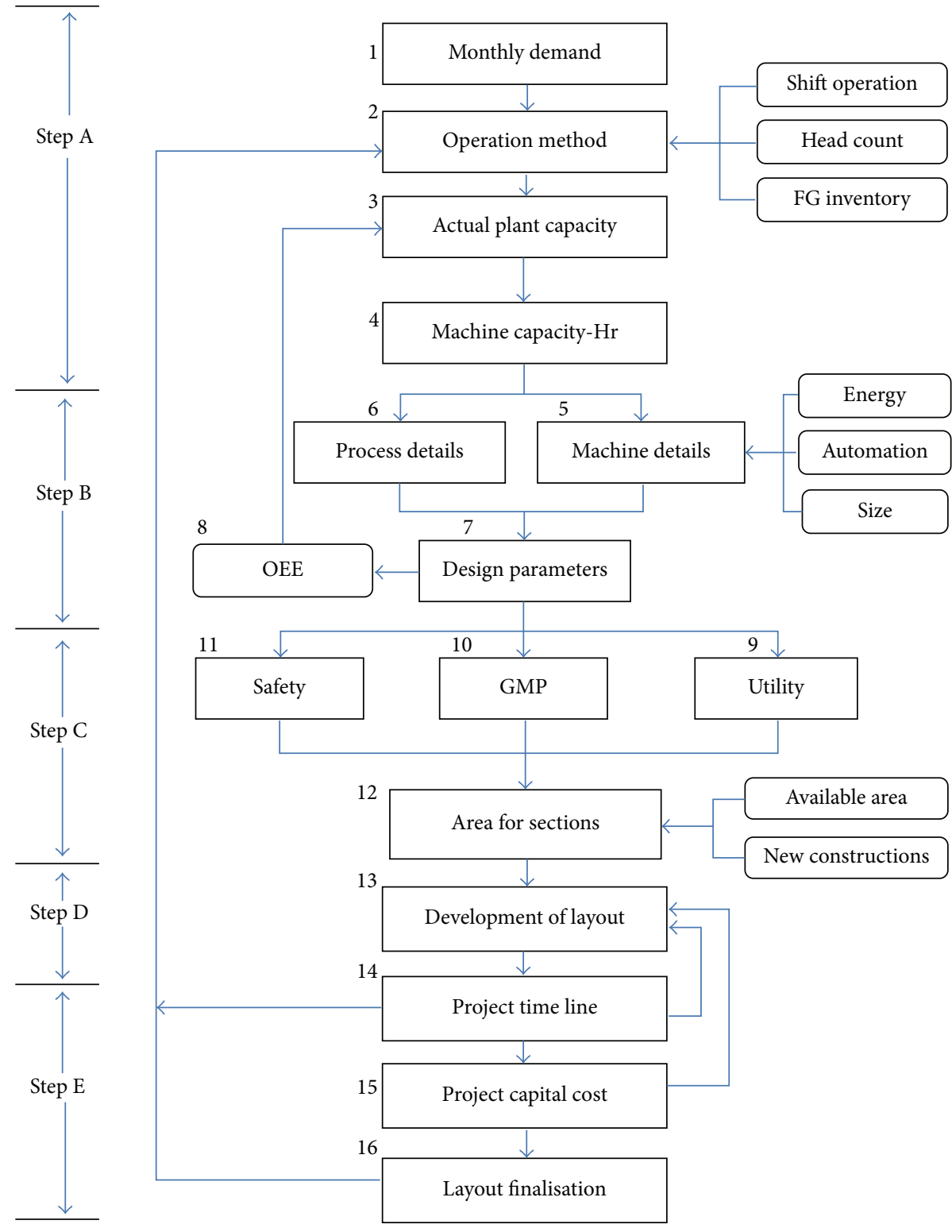

Figure 2: Proposed framework.

for execution are other limitations often overlooked in the literature. Hence, there has to be greater understanding of these limitations when designing a layout.

The proposed framework illustrated in Figure 2 was thus developed to support the industrial designers to obtain the required information in a systematic manner. It consists of five main steps. Step A is concerned with the capacity of the required machinery. Step B addresses the issue of design parameters of the manufacturing process. Step C helps to generate space requirements for different sections of the layout. Step D considers the layout alternatives and Step E is dedicated to the selection of the most practical layout from the available options.

Step A. Details of six items are to be known to derive the machinery capacity: monthly demand, shift operation information, headcount of personnel, finished goods inventory, actual plant capacity, and machine capacity. Here, shift operation, head count, and the finished goods inventory constitute the operation method.

Step B. This is to consolidate the process details and machine details for the layout design. Energy requirement, level of automation, and the size of machines are the determining factors of machine details. Process and machine details decide the design parameters for the layout design. When the OEE is known, this information can be used to feed information to obtain the actual plant capacity.

Step C. This helps to identify the required floor area for each section in the layout. In order to decide this, safety, GMP, and utility areas need to be assessed. The available 
area and possible new construction for additional area are then searched and finally the optimum mix of areas for the different sections is determined.

Step D. Layout development is carried out at this stage. A suitable layout design tool has to be used to develop an optimum solution to the facility layout problem. Relationship diagrams, from-to matrix, and other layout development methods can be used to develop the layout [3]. This is where a model for layout planning can have a positive impact.

Step E. The final step takes care of the practical aspects that affect the layout. The financial feasibility and feasibility as a project to implement the selected layout are emphasised in this step.

\section{Development of the Model}

A model can be developed for the food industry to support Step D in the framework. Layout generation and evaluation are often challenging and time consuming due to their inherent multiobjective nature and complexity in the data collection process $[16,17]$ as in [18]. Past and emerging research is aimed at developing methodologies to meet these needs [3, 7]. For example, [7] discusses an algorithmic approach to layout design. However, algorithmic approaches have focused mainly on minimising flow distance in order to minimise material handling costs [3]. On the other hand, procedural approaches have relied heavily on experience of experts [3]. Therefore, neither an algorithmic nor a procedural layout design methodology is necessarily effective in solving practical design problems [9] as cited in [19].

Food processing factories are governed by guidelines developed by regulators. These guidelines describe the minimum requirement relevant for the industry. GMP for industry is developed based on these guidelines and the latest developments made in relation to the industry [12]. These mandatory GMP have to be adopted by the food manufacturing factories to comply with product safety standards and ensure hygiene. Hence there are many similarities in these factories. These similarities can help to develop a common model layout applicable for the food processing factories.

As discussed earlier, the food industry norms have to be followed in designing factory layouts for food manufacturing and segregation of work areas is important for the food processing industries as they are characterised by a continuous change in volume, type, and mix of products due to constantly changing market requirements [4]. On top of this, many critical control points are present in the food processing industry. These have been identified as hazards for the manufacturing process. Hence there should be adequate controls to mitigate the risk of contamination. The site layout plays an important role in this risk mitigation process. Thus, basic sections of food processing facilities were identified as primary manufacturing, secondary packing, warehouse, utility area, and administration.

The hazards identified in HACCP [11] are biological hazards (e.g., bacteria, yeasts, and moulds), chemical hazards (e.g., cleaning chemicals and lubricating fluids), and physical

\begin{tabular}{|l|c|c|}
\hline Section & Colour & Code R, G, B \\
\hline Primary & & $255,255,0$ \\
\hline Secondary & & $0,255,0$ \\
\hline Administration & & $0,255,255$ \\
\hline Utility & & $255,0,255$ \\
\hline Stores & & $255,191,127$ \\
\hline
\end{tabular}

Figure 3: Colour scheme to identify the five basic sections of a layout.

hazards (e.g., glass, insects, pests, metal, and dust). Layouts for food processing facilities should be designed to minimise risks due to the above hazards. The product is exposed to the environment at the primary manufacturing area. Thus, it is the area, which poses the highest risk for hygiene in the manufacturing process, and risk mitigation steps are essential to prevent contamination. Environmental conditions in terms of humidity, temperature, and particulate levels and the barometric pressure have to be closely monitored and maintained within the primary manufacturing section. Furthermore, the primary manufacturing area has to be completely separated from the other areas to control the risk of contamination. Employees moving to the primary manufacturing area should undergo uniform changes as required by GMP requirements for the manufacturing processes and adequate facilities are needed for this activity. Personnel entry and the material entry paths to the factory also have to be clearly segregated. This is a GMP and safety requirement in the industry. The other four sections need to be placed to provide maximum assistance to primary manufacturing while ensuring the food hygiene requirements. Thus, it is important to clearly define the above five basic sections of a food processing factory in a layout drawing. A colour scheme as shown in Figure 3 is also proposed in order to identify the basic sections. Food processing comprises many simultaneous activities and can have complex layouts. These can take many shapes. Therefore, the proposed colour scheme can potentially simplify the layout design process by enabling easy visualisation.

4.1. Layout Model. The layout model for food manufacturing, called the "diamond model" (Figure 4), was developed by sequentially locating the five basic sections discussed above. The traditional method of locating departments is based mainly on two optimisation factors, the adjacency or distance travelled. However, in this model, food safety (or GMP) becomes the main criterion for optimisation to locate departments. Other traditional factors are considered as secondary.

Existing layouts present in the food industry were observed $(n=4)$ and evaluated in designing the model layout. Many layouts indicate that the high risk and low risk areas are protected from the external environment by only a solid wall. This can lead to pest ingression, cross contamination, and direct contamination. Most of the time, 


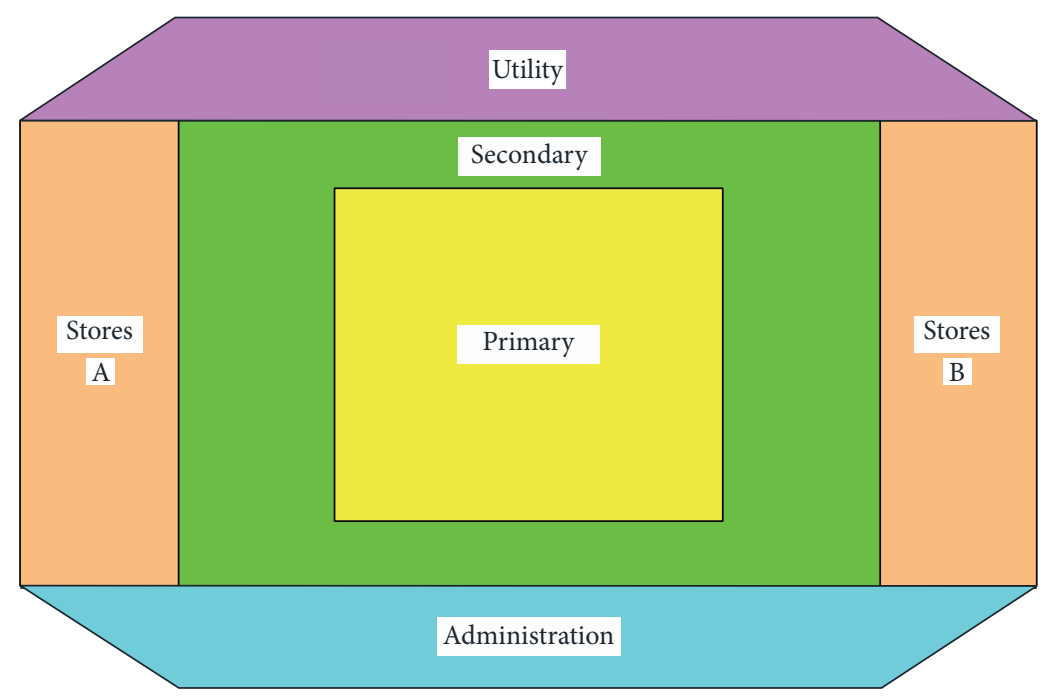

FIGURE 4: Diamond model.

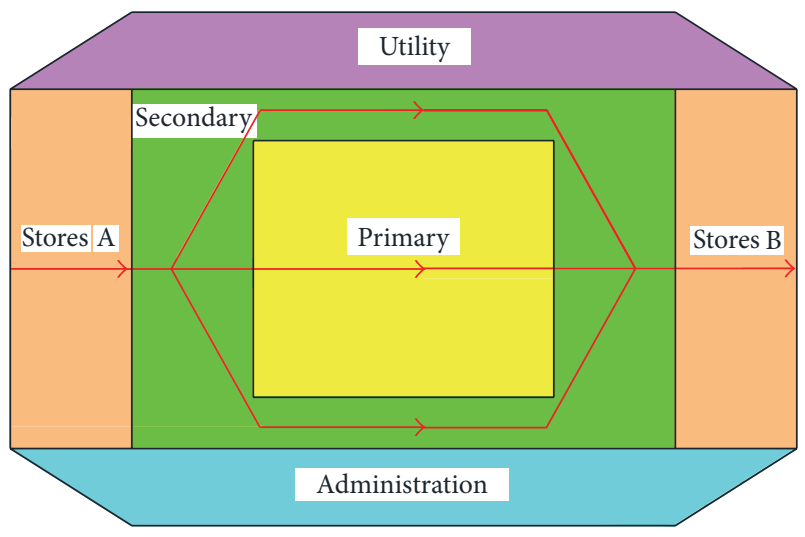

Figure 5: Material movement in diamond model.

the utility system is located away from the high risk area; hence, heating, ventilating and air conditioning (HVAC) ducting, steam lines, and compressed air lines should move to this area through wall openings. This poses a risk to the food processing plant. These risk factors can be significantly controlled by surrounding the primary manufacturing area with the secondary manufacturing area. The secondary manufacturing area then has to be surrounded with other sections of the factory. This prevents the external contaminants from reaching the primary and secondary manufacturing areas. This reduces the risk due to biological, chemical, or physical contamination. Finally, the utility, administration, and warehouse areas should be attached to the secondary manufacturing area.

The diamond model layout shown in Figure 4 ensures correct material and personnel movement within the factory. As indicated in Figure 5, the material flow is from left to right. The raw material and packing material received at the stores in left side are converted to finished goods and transferred to the stores at the right end of the layout. Personnel entry to the

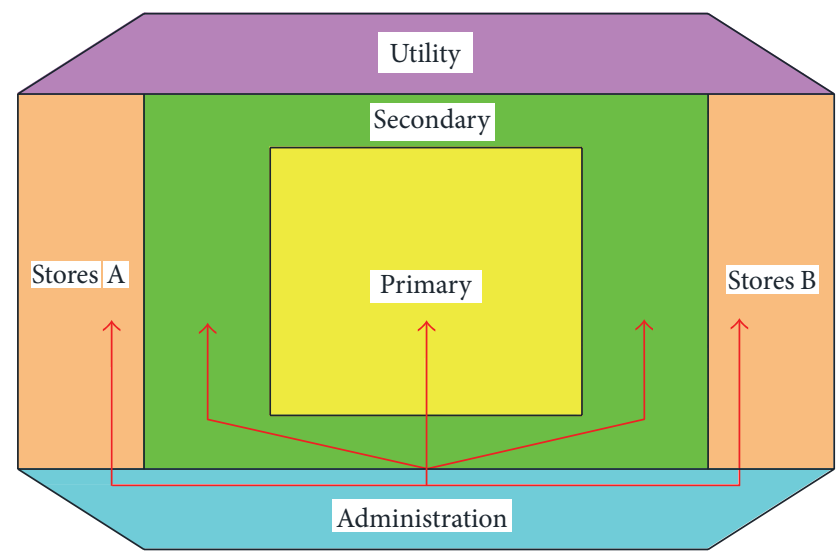

FIgURE 6: Personnel movement in diamond model.

facility is from the administration area at the bottom as shown in Figure 6. Thus, this model minimises cross contamination and streamlines personnel and goods movement on the factory floor.

The model in Figure 4 clearly shows the five key areas of a food processing factory. These five areas encompass all functions of typical food processing factories. The space allocation for each of these sections varies from the actual space requirements as per the manufacturing process. This is performed when the framework is applied to identify the space requirements in the layout.

4.1.1. Primary Manufacturing Area. The product that arrives from the secondary manufacturing area is exposed to the facility environment in the primary manufacturing area, drastically increasing the contamination risk and thus it should be the most protected area of the manufacturing process. Hence the above model locates the primary manufacturing area at the centre of the layout to isolate it from the outside environment as much as possible. 
The product usually enters the primary area through pressurised air locks. Personnel also must enter through air locks and undergo gowning changes. They need to wear head covers, shoe covers, masks, and gloves as appropriate to the manufacturing process before entering the primary manufacturing area. Hand-wash stations also need to be established at the entry to the primary manufacturing area. Furthermore, entrances to this area need to have air curtains to prevent outside air from entering the high risk area.

As mentioned, the product is exposed at the high risk primary manufacturing area [11]. Thus, the air in this section must be conditioned as a standard. The particle count in air is controlled through high efficiency particle absorption (HEPA) filters and relative humidity is controlled as per the process norms. The air pressure is also maintained at a slightly higher level than that of the secondary manufacturing area to prevent particulates from getting into the primary manufacturing area. The pressure difference between low and high risk areas is kept between 5 and $15 \mathrm{~Pa}$ so that the air flows to the low risk area from the high risk area is $1.5 \mathrm{~m} / \mathrm{sec}$ or greater through openings [11].

4.1.2. Secondary Manufacturing Area. The product is first exposed to the facility environment in the secondary manufacturing area. The raw material enters the secondary manufacturing area from the stores. The product being manufactured at the primary manufacturing area is usually in its primary packing when it reaches the secondary manufacturing area, and the secondary manufacturing area is the entity in which the final packing of the product takes place. Then the product in its final packing is sent to the finished goods warehouse. Hence, air locks need to be placed between the stores and secondary manufacturing area to prevent contamination through leaking air. These air locks also prevent pests from entering the secondary manufacturing area [11].

The personnel entry to the secondary manufacturing area is from the administration area and that too needs to be through air locks. It is also usually equipped with a gowning regime to change to designated clothes before entering the secondary manufacturing area. Thus, the gowning area needs to be appropriately placed in the administration section of the layout.

The air quality of the secondary manufacturing area is maintained as specific to the manufacturing process. The same pressure difference is maintained between the primary and secondary manufacturing areas so that the air flows to the low risk area from the high risk area [11]. Here, it is also good practice to maintain positive pressure (e.g., $0.02 \mathrm{~mm} \mathrm{H}_{2} \mathrm{O}$ ) with respect to the utility, stores, and office areas. The positive pressure prevents outside air from reaching the secondary manufacturing area. This prevents possible contamination of the product.

4.1.3. Warehouse. The warehouse holds raw material and packing material for the manufacturing process and finished goods. The warehouse is divided into two sections: Store A and Store B. Store A keeps the raw material and packing material. All these materials are in the quarantine area until they pass the quality check. Then these materials are released for manufacturing. Store B holds finished goods. The finished goods are released from the store once the quality checks are over. The environmental conditions in the store areas can differ to suit the products being manufactured. For example, these can be cold rooms, chilled rooms, or air conditioned according to the requirement for raw material and finished goods.

The goods movement from the stores is in one direction. There is no back tracking or criss-crossing of material movement on the layout. As shown in Figure 5 for material movement, the raw and packing material entering Store A move through the manufacturing process and reach Store $\mathrm{B}$ as finished goods. Therefore, in order to prevent cross contamination, personnel movement needs to be restricted or controlled and thus changing room facilities need to be placed at appropriate locations.

4.1.4. Utility Area. This area hosts all utilities and the engineering department of the organisation. Utility equipment includes components such as air handlers for the heating, ventilating and air conditioning (HVAC) system, boilers, air compressors, chillers, and water purification plants that support the manufacturing process. According to the observations, there is no need for frequent direct access to the secondary packing area from the utility area. Therefore, sealed type emergency exit doors can be fixed if required.

4.1.5. Administration Area. This area holds the facilities such as the main administration office, changing rooms for employees, canteens, washrooms, toilets, and first aid rooms. Employees use the changing room in the administration area and wear the factory uniform and sanitise their hands before entering the secondary manufacturing area. Employees enter the stores from a separate entrance after changing their uniforms. This area is not treated as a production area. Offices are also located in this area and the layout can be designed so that the offices have a direct view of the manufacturing area through glass panels. This facilitates good visibility of the production area while preventing cross contamination. Visitors' viewing area of the production process can also be located in this area.

4.1.6. Personnel and Goods Movement. Employee movement within the facility in the diamond model is shown by arrows in Figure 6. The employees working in different sections can access them through the administration area. Those who work at the primary and secondary manufacturing areas can enter through air locks. Access to the primary manufacturing area is only through the secondary manufacturing area.

Goods movement in the diamond model is depicted in Figure 5. Goods first reach the warehouse as raw and packing material. These are stored in Store A. Then they move towards the secondary manufacturing area. Removal of packaging, weighing, and batch preparation takes place in this area.

Then the raw material ready for processing is moved to the primary manufacturing area. Once the manufacturing 
process is complete and primary packing is finished, the final product moves into the secondary packing area. Then secondary packing takes place in the secondary manufacturing area. This includes tasks such as pasting labels, printing information, packing into shippers, shrink wrapping, and palletising. Then the finished product moves to Store B, and it is ready for dispatch.

\section{Evaluation of the Framework and Model: Case Study}

The proposed framework for layout design and the proposed diamond model were used to rearrange a facility for food processing. The factory packs bulk malted milk powder into three stock keeping units (SKUs): Sachets, jars, and bag in box (BIB).

Usability of the above framework and the model was tested and validated during this layout renovation project. The framework was used to obtain the layout design requirements and consider other necessary parameters for the layout design. The diamond model was then used as the guideline in designing the layout. Stages of the manufacturing process were identified as primary, secondary, warehouse, utility, and administrative. Machinery and furniture were identified for these specific areas.

\section{Results and Discussion}

The proposed framework conveniently facilitates handling the aspects of data requirement in order to arrive at a decision on the layout. The OEE, maximum production capacity and finally the area requirement for the layout were obtained by following the framework. One advantage when modifying an existing layout is the knowledge of most of data related to machine performance and the process. Hence, machine capacity, physical size of machinery, process details, and area requirement for sections could be obtained easily. Furthermore, this information was accurate as no assumptions were made when obtaining data.

The proposed diamond model resolved the major decision points in the FLP. The location of the five sections of the factory was clear. The process equipment to be positioned in these five sections (i.e., primary manufacturing, secondary manufacturing, utility, warehouse, and administration) was clearly known as these were identified when the framework was applied in the first stage. This simplified the process of providing the solution to the FLP. A process-oriented layout was used in the arrangement of the equipment in the five sections. The relationship chart and the distance chart helped to reach the best location for the equipment in the layout.

Table 1 lists the improvement observed in the facility in terms of the key performance indicators (KPIs) after the implementation of the layout change.

As per the results shown in Table 1, it is observed that the new layout has helped to increase the overall equipment efficiency of the factory. This is due to reduction of down time in the process. Supervision of machines became relatively easy as similar machines were grouped together.
TABLE 1: KPI chart for factory.

\begin{tabular}{lcc}
\hline Description & Before & After \\
\hline Overall equipment efficiency, OEE & $60 \%$ & $82 \%$ \\
Material waste per batch, $\%$ & $2.4 \%$ & $0.8 \%$ \\
Carbon dioxide emission, $\mathrm{kg} / \mathrm{MT}$ & 62.5 & 51.6 \\
\hline
\end{tabular}

TABLe 2: Travel distance comparison.

\begin{tabular}{lccc}
\hline SKU & \multicolumn{3}{c}{ Distance $(\mathrm{m})$} \\
& Before & After & Improvement \\
\hline Sachet & 628 & 364 & $42 \%$ \\
Bulk powder & 1,603 & 1,263 & $21 \%$ \\
BIB & 924 & 464 & $50 \%$ \\
Jar & 842 & 475 & $44 \%$ \\
Total & 3,398 & 2,565 & $36 \%$ \\
\hline
\end{tabular}

TABle 3: Travel distance into weight comparison.

\begin{tabular}{lccc}
\hline \multirow{2}{*}{ SKU } & \multicolumn{3}{c}{ Distance into weight (mkg) } \\
& Before & After & Improvement \\
\hline Sachet & 156,449 & 126,968 & $19 \%$ \\
Bulk powder & 800,430 & 629,388 & $21 \%$ \\
BIB & 403,726 & 196,141 & $51 \%$ \\
Jar & 145,354 & 114,172 & $21 \%$ \\
Total & $1,505,960$ & $1,066,669$ & $29 \%$ \\
\hline
\end{tabular}

Communication of machine failures and production issues was efficient due to close proximity location of machinery. This helped supervisors and technicians to respond promptly to maintenance activities and provide solutions to avoid machine down time.

The comparison of from-to matrix (travel distance) and the travel distance to weight before and after the layout change is given in Tables 2 and 3, respectively. Those tables indicate the reduction in the distance travelled and the weight into distance travelled after the modification. For instance, the cumulative travel distance of BIB area was reduced by $36 \%$ and the cumulative distance into weight was reduced by $29 \%$. Similarly all the parameters of Jar, Sachet, and BIB filling process were reduced in a favourable manner in the new layout.

The changes improved ergonomics of the workplace as well. For example, pulling of heavy pallet trucks for long distances was reduced thus providing a more relaxing working environment. However, the level of improvement needs to be verified.

The layout development was performed considering the $\mathrm{OEE}$ as $60 \%$. Once the factory started operating after modification, the OEE gradually increased to $82 \%$. The OEE was stable at $82 \%$ after one year of operation. This increased the capacity of the facility. However, other determining factors such as equipment and maintenance may also have contributed towards the improvement of OEE and further investigation to ascertain that the contribution due to facility change is required. 
Allocation of area for sections of the diamond model can be changed as per the area requirement for each section. This area requirement can be derived from the framework. However, the location of sections as per the model is recommended. In the modified processing plant, the primary area was located in a corner of the layout that could create contamination risks as well as material and personnel movement issues. The single wall protection from the external environment can be breached due to weak links such as unsealed windows, glass partitions, utility pipes, and HVAC system. This leaves the primary manufacturing area vulnerable to contamination.

\section{Conclusion}

Finding solutions to the facility layout problem (FLP) is difficult. This becomes more difficult in the food processing industry due to industry-specific regulatory needs such as food safety, hygiene, and GMP requirements. Thus, the aim was to develop a method to help layout design specific to the food processing industry.

A set of operations unique to the food processing could be identified by considering the food safety risk level. Various operations could be grouped into five different areas: primary manufacturing, secondary manufacturing, utility, warehouse, and administration. These five areas have different ventilation, building finishing, access control, and lighting requirements to mitigate the food safety risks. Considering the unique requirements, a framework was developed that considers specific requirements of the food processing industry and collects data in a systematic manner to support resolving the FLP. Later, a model named the diamond model was developed, which included the five different areas identified.

In a case study, the framework helped to collect vital data relevant to factory operations. It was also helpful in the decision making process to resolve the FLP. The diamond model further simplified the FLP by splitting the plant operation into the five major sections and helped locating each section in the layout. The improved layout resulted in an increase in the overall equipment efficiency (60\% to $80 \%)$, a decrease in material waste (2.4\% per batch to $0.8 \%)$, and a reduction of $\mathrm{CO}_{2}$ emissions per metric ton of production ( 62.5 to $51.6 \mathrm{~kg} / \mathrm{MT}$ ).

The approach was only tested in an existing factory modification. However, it should be further evaluated when developing a completely new facility for food processing.

\section{Competing Interests}

The authors declare that they have no competing interests.

\section{References}

[1] A. Drira, H. Pierreval, and S. Hajri-Gabouj, "Facility layout problems: a survey," Annual Reviews in Control, vol. 31, no. 2, pp. 255-267, 2007.
[2] S. P. Singh and R. R. K. Sharma, "A review of different approaches to the facility layout problems," International Journal of Advanced Manufacturing Technology, vol. 30, no. 5-6, pp. 425-433, 2006.

[3] A. Shahin and M. Poormostafa, "Facility layout simulation and optimization: an integration of advanced quality and decision making tools and techniques," Modern Applied Science, vol. 5, no. 4, pp. 95-111, 2011.

[4] D. P. van Donk and G. Gaalman, "Food safety and hygiene: systematic layout planning of food processes," Chemical Engineering Research and Design, vol. 82, no. 11, pp. 1485-1493, 2004.

[5] T. Wijtzes, K. Van'T Riet, J. H. J. Huis In'T Veld, and M. H. Zwietering, "A decision support system for the prediction of microbial food safety and food quality," International Journal of Food Microbiology, vol. 42, no. 1-2, pp. 79-90, 1998.

[6] S. P. Daf and D. R. Zanwar, "Analysis and improvement in plant layout for effective production in manufacturing industries," International Journal of Technology, vol. 3, no. 1, pp. 19-28, 2013.

[7] C. S. Tak and L. Yadav, "Improvement in layout design using SLP of a small size manufacturing unit: a case study," IOSR Journal of Engineering, vol. 2, no. 10, pp. 1-7, 2012.

[8] A. K. Jain, V. Khare, and P. Mishra, "Facility planning and associated problems: a survey," Innovative Systems Design and Engineering, vol. 4, no. 6, pp. 1-8, 2013.

[9] T. Yang, C.-T. Su, and Y.-R. Hsu, "Systematic layout planning: a study on semiconductor wafer fabrication facilities," International Journal of Operations \& Production Management, vol. 20, no. 11, pp. 1359-1371, 2000.

[10] W. Xie and N. V. Sahinidis, "A branch-and-bound algorithm for the continuous facility layout problem," Computers and Chemical Engineering, vol. 32, no. 4-5, pp. 1016-1028, 2008.

[11] S. Jiang and A. Y. C. Nee, "A novel facility layout planning and optimization methodology," CIRP Annals-Manufacturing Technology, vol. 62, no. 1, pp. 483-486, 2013.

[12] J. Holah, Guidelines for the Hygienic Design, Construction and Layout of Food Processing Factories, Campden \& Chorleywood Food Research Association Group, Gloucestershire, UK, 2003.

[13] M. D. Pierson and D. J. Corlett, HACCP: Principles and Applications, Van Nostrand Reinhold, New York, NY, USA, 1992.

[14] H. Hofstra, J. M. B. M. van der Vossen, and J. van der Plas, "Microbes in food processing technology," FEMS Microbiology Reviews, vol. 15, no. 2-3, pp. 175-183, 1994.

[15] P. J. Fellows, Food Processing Technology Principles and Practice, Woodhead, Cambridge, UK, 2009.

[16] L. J. Unnevehr and H. H. Jensen, "The economic implications of using HACCP as a food safety regulatory standard," Food Policy, vol. 24, no. 6, pp. 625-635, 1999.

[17] L. C. Lin and G. P. Sharp, "Quantitative and qualitative indices for the plant layout evaluation problem," European Journal of Operational Research, vol. 116, no. 1, pp. 100-117, 1999.

[18] L. C. Lin and G. P. Sharp, "Application of the integrated framework for the plant layout evaluation problem," European Journal of Operational Research, vol. 116, no. 1, pp. 118-138, 1999.

[19] T. Yang and C. Kuo, "A hierarchical AHP/DEA methodology for the facilities layout design problem," European Journal of Operational Research, vol. 147, no. 1, pp. 128-136, 2003. 


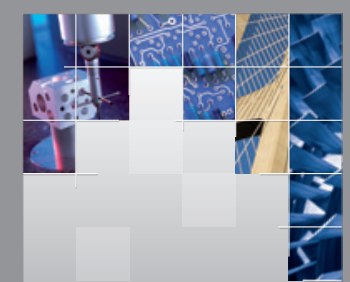

\section{Enfincering}
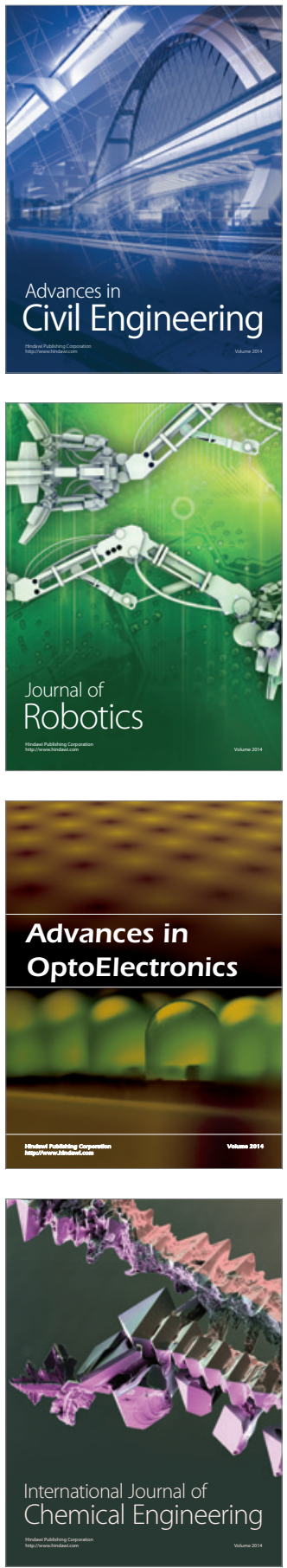

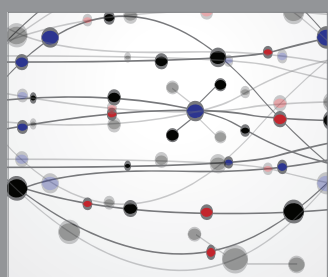

The Scientific World Journal

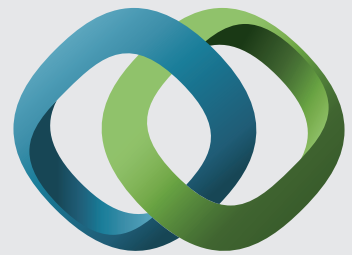

\section{Hindawi}

Submit your manuscripts at

http://www.hindawi.com
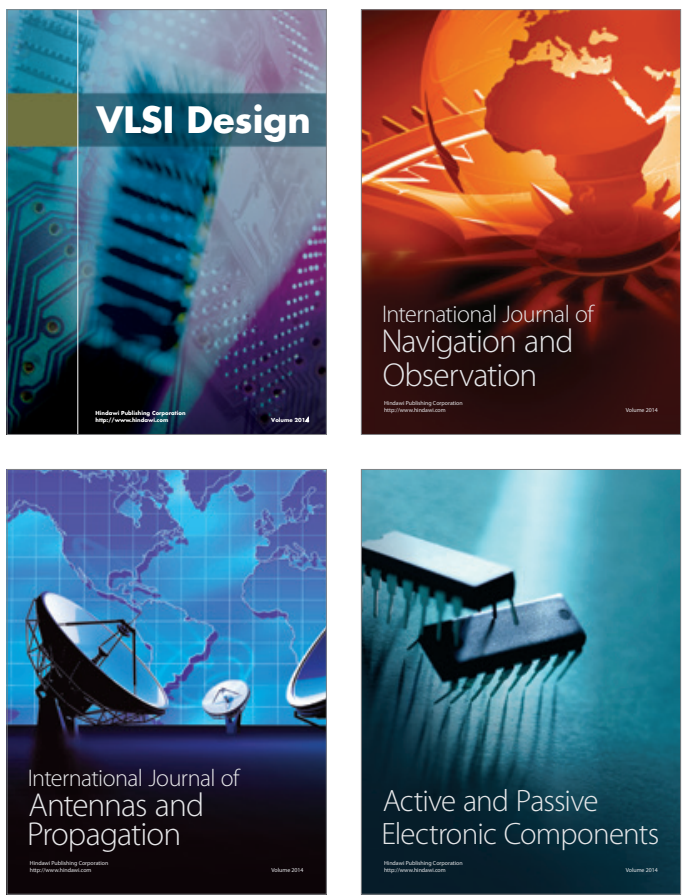
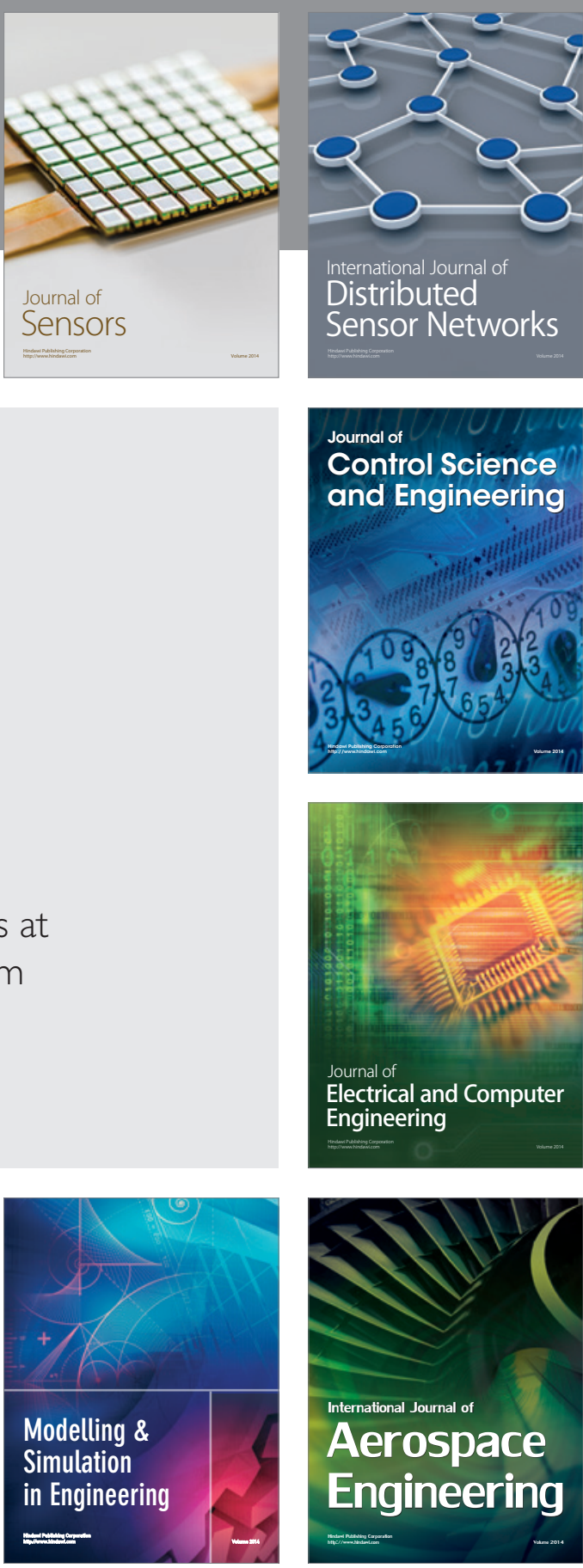

International Journal of

Distributed

Sensor Networks

Journal of

Control Science

and Engineering
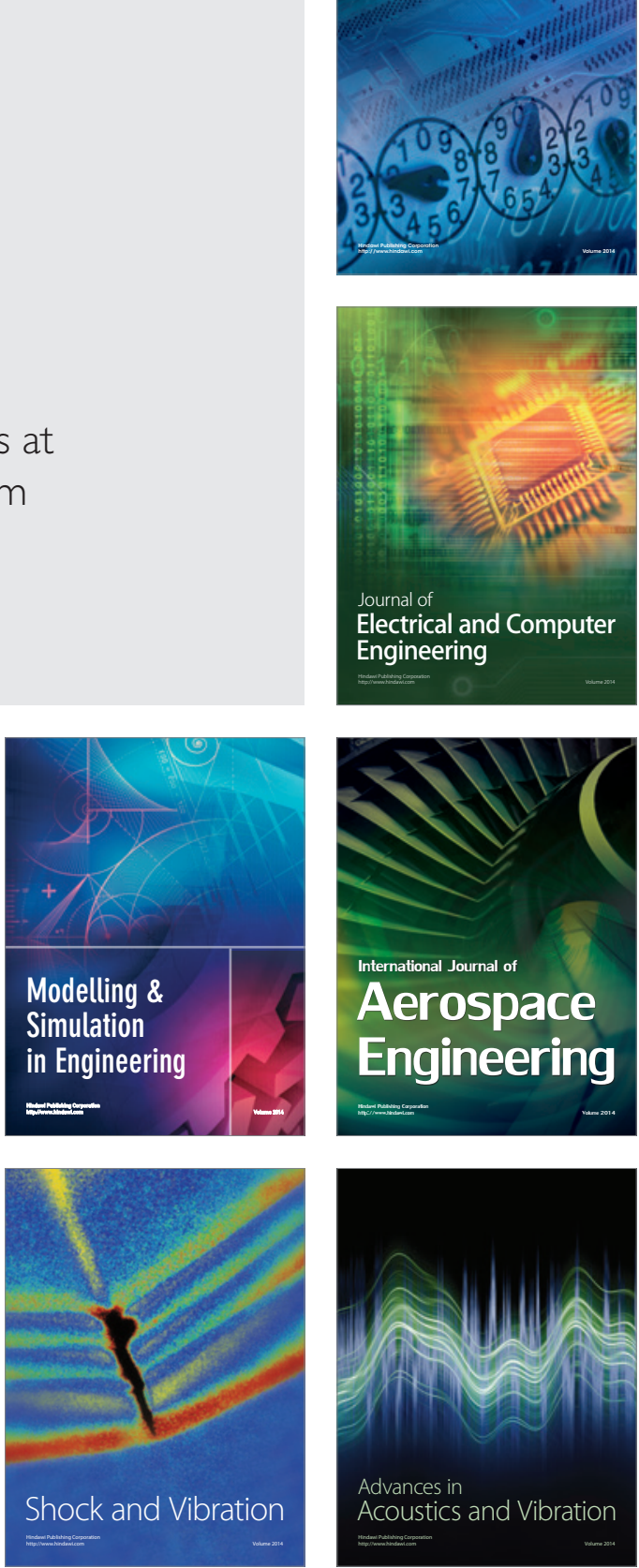